\title{
Sea-ice thickness in the Weddell Sea, Antarctica: a comparison of model and upward-looking sonar data
}

\author{
Angelika H.H. RENNER, ${ }^{*}$ Victoria LYTLE \\ CliC International Project Office, Norwegian Polar Institute, Polar Environmental Centre, NO-9296 Tromsø, Norway \\ E-mail: ahhre@bas.ac.uk
}

\begin{abstract}
Sea-ice thickness is a key parameter for estimates of salt fluxes to the ocean and the contribution to global thermohaline circulation. Observations of sea-ice thickness in the Southern Ocean are sparse and difficult to collect. An exception to this data gap is time-series data from upwardlooking sonars (ULS) which sample the drifting sea ice continuously. In this study we use ULS data from ten different locations over periods ranging from 9 to 25 months to compare with model data. Although these data are limited in space and time, they provide a qualitative indication of the ability of global climate models (GCMs) to adequately represent Southern Ocean sea ice. We compare the ULS data to output from four different GCMs (BCCR-BCM2.0, ECHAM5/MPI-OM, UKMO-HadCM3 and NCAR CCSM3) which were used for the Fourth Assessment Report of the Intergovernmental Panel on Climate Change. They simulate the ice thickness reasonably well, but in most cases average model ice thickness is less than thicknesses derived from ULS data. The seasonal cycle produced by the models correlates well with the ULS except for locations near Maud Rise, where in summer the ULS find a low concentration of thick ice floes. This overly thin ice will have implications for both the salt flux to the central Weddell Sea during the growth season and the freshwater flux during the melt season. Using satellite-derived ice-drift data to calculate transports in the Weddell Sea, we find that the underestimation of ice thickness results in underestimated salt fluxes.
\end{abstract}

\section{INTRODUCTION}

Sea-ice thickness remains a parameter which is difficult to quantify on a regional or global scale. While satellite sensors do a reasonable job of estimating properties such as sea-ice extent, concentration and velocity, sea-ice thickness is not yet routinely measured from space. For climate models, sea ice plays an important role in estimating ocean salt fluxes, ocean-atmosphere heat fluxes and momentum transfer, yet validation of ice thickness in models is severely limited by available data.

Different airborne and in situ techniques have been used to estimate thickness, including electromagnetic techniques (Haas and others, 1997), drillhole measurements (e.g. Lange and Eicken, 1991; Jeffries and Adolphs, 1997) and satellite altimetry (Laxon and others, 2003; Kwok and others, 2006). Submarine data have also been used in the Arctic (Wadhams and Horne, 1980; Rothrock and others, 1999). Each of these techniques can be used to estimate regional ice thickness, but data are often collected over a relatively short period and provide only a 'snapshot' of the sea-ice thickness. Datasets to evaluate the time evolution of sea ice can be compiled from a series of measurements collected at different times as done, for example, in the Antarctic Sea Ice Processes and Climate (ASPeCt) database. However, except in a few instances where intensive field campaigns collected continuous data (e.g. Ice Station Weddell (ISW; Gordon and Lukin, 1992), Surface Heat Budget of the Arctic Ocean (SHEBA; Perovich and others, 2003)), time series are plagued by gaps and inconsistencies. Timmermann and others (2004) used ASPeCt sea-ice thickness data to evaluate a global coupled sea-ice-ocean model. However, their study suffers from

*Present address: British Antarctic Survey, Natural Environment Research Council, Madingley Road, Cambridge CB3 OET, UK. seasonal or interannual biases, mostly towards thin ice, and errors due to limited accessibility and choice of ship tracks in the ASPeCt dataset. This study complements the work by Timmermann and others (2004) by using a continuous time series, hence avoiding the seasonal and logistical bias while reducing the areal coverage of available observations.

Beginning in the late 1980s, time series of ice draft were created using upward-looking sonars (ULS), moored to the sea floor, which were deployed in both the Arctic and Southern Ocean (e.g. Strass and others, 1998; Vinje and others, 1998). ULS data, while confined to a single location, have the ability to continuously collect data over multiple seasons or years, and provide a time evolution of sea-ice thickness (Melling and others, 1995). In particular, they are able to capture the seasonal evolution of the ice thickness. ULS instruments have a relatively small footprint on the order of meters. However, because sea ice is highly mobile and drifts across this footprint, the instruments measure a large number of different ice floes. As with all measurements, ULS data have some drawbacks, especially in the Southern Ocean where they must be moored relatively deep to avoid iceberg impacts. Harms and others (2001) combined ice-thickness data derived from ULS measurements with estimates of seaice salinity from ice-core data to estimate ice and salt mass transport at each of the mooring locations in the Weddell Sea. Drinkwater and others (2001) used the same ULS data in combination with satellite backscatter data to derive an empirical relationship between ice thickness and the rate of change of backscatter with incidence angle, and included satellite-derived ice drift to estimate ice volume fluxes.

Comparisons of model ice concentrations and extent to observations from satellites have been made in various studies (e.g. Lemke and others, 1997; Timmermann and others, 2006), recently also including the data used for this study (e.g. Arzel and others, 2005; Holland and Raphael, 


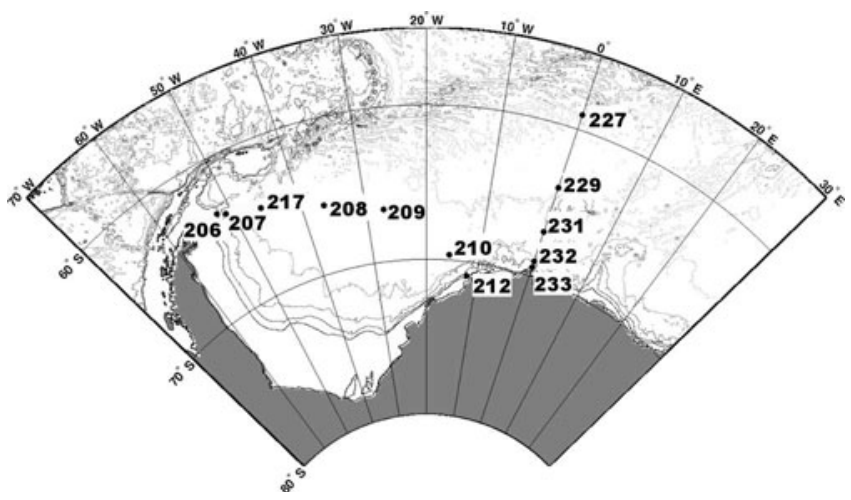

Fig. 1. Positions and numbers of the AWI ULS instruments in the Weddell Sea.

2005; Parkinson and others, 2006). Connolley (2005) used ice concentrations derived from ULS data and found them to be reliable.

We do not intend to re-evaluate the datasets, or improve on estimates from other studies (e.g. Drinkwater and others, 2001; Harms and others, 2001). We rather address the questions: how well do global coupled models reproduce sea-ice thickness data on a seasonal cycle? and how does this influence the salt fluxes associated with sea-ice formation and melt which largely determine the influence of sea ice on the ocean thermohaline circulation? Given the paucity of sea-ice thickness observations, and the importance of salt fluxes for the ocean thermohaline circulation, it is important to use even the limited amount of available observations to better understand models.

\section{DATA SOURCES}

Data collected by 14 moored ULS are used to derive ice thickness. The ULS instruments were deployed in the Weddell Sea by the Alfred Wegener Institute (AWI) along two transects during 1990-94 and 1996-98 (see Fig. 1). Transect 1 consists of eight instruments placed across the Weddell Sea from the tip of the Antarctic Peninsula in the west to Cape Norvegia in the east. Transect 2 is comprised of six instruments placed in a north-south line along the prime meridian. The data were processed as described by Strass and others (1998) before being made available at the US National Snow and Ice Data Center (NSIDC), Boulder, CO, via http://nsidc.org/data/g01359.html. During processing, a bias in ice draft was removed and the errors reduced to $0.04 \mathrm{~m}$ for ice draft and $1.5 \%$ for percent ice coverage. Detailed information on the dataset and the instruments is given in Strass and Fahrbach (1998), Strass and others (1998), and Harms and others (2001).

Output from global coupled ocean-atmosphere models used for the Fourth Assessment Report of the Intergovernmental Panel on Climate Change (IPCC) is provided via https://esg.IInl.gov:8443/index.jsp. Of the 18 models for which, at the time of writing, sea-ice thickness data are available, we selected 4, namely the Bjerknes Center for Climate Research Bergen Climate Model, version 2 (BCCRBCM2.0, hereafter referred to as BCCR); ECHAM5 coupled to the Max Planck Institute Ocean Model (ECHAM5/ MPI-OM, hereafter ECHAM); The Hadley Centre/UK Meteorological Office Climate Model, version 3 (UKMO$\mathrm{HadCM} 3$, hereafter HADCM); and the Community Climate System Model, version 3.0, of the US National Centers for Atmospheric Research (NCAR CCSM3, hereafter NCAR). These were randomly selected to cover a range of different approaches to simulate sea ice as shown in Table 1, where a summary of the characteristics of the sea-ice components is given. Because of the limited observational dataset, it is not possible to make a comprehensive evaluation of the model; however, it is possible to gain some insight into the characteristics of the sea-ice portions of the models. We use monthly mean sea-ice concentration and thickness from the 'Climate of the 20th Century' experiment (20c3m). For ECHAM5/MPI-OM and UKMO-HadCM3, sea-ice data from two runs, initiated using different years from the control run (PIcntrl), were provided. They are referred to as ECHAM 1 and 2, and HADCM 1 and 2, respectively.

For calculating sea-ice volume and salt fluxes, we used SSM/I ice motion data available at http://imkhp7.physik.unikarlsruhe.de/ eisatlas. These data were derived from SSM/I Optimal Interpolated data, converted to longitude-latitude coordinates and temporally averaged, in this case to monthly means. Data are available for the months MarchNovember 1979-97.

Table 1. Model overview

Model

Sea-ice model characteristics

Thermodynamics/dynamics/salinity

BCCR-BCM2.0, Bjerknes Centre for Climate Research, Norway

NCAR CCSM3, National Center for Atmospheric Research, USA

ECHAM5/MPI-OM, Max Planck Institute for Meteorology, Germany

UKMO-HadCM3, Hadley Centre for Climate Prediction and Research/Meteorological Office, UK
Horizontal: $0.375^{\circ}$ lat. $\times 0.125-0.375^{\circ}$ long . (four ice model gridcells within one ocean gridcell); vertical: one snow layer, one ice layer, one ice-thickness class

Horizontal: nominal $1^{\circ}$; vertical: one snow layer, four ice layers, five ice-thickness classes, one open-water class

Horizontal: $1.5^{\circ}$ lat. $\times 1.5^{\circ}$ long.; vertical: one snow layer, one ice layer, one ice-thickness class Horizontal: $1.25^{\circ}$ lat. $\times 1.25^{\circ}$ long.; vertical: one ice layer
Thermodynamics: Drange and Simonsen (1996); dynamics: viscous-plastic (Hibler 1979; Harder, 1996); salinity: 6 psu

Thermodynamics: Bitz and Lipscomb (1999); dynamics: elastic-viscous-plastic (Hunke and Dukowicz, 1997); salinity: 4 psu

Thermodynamics: Semtner (1976); dynamics: Hibler (1979); salinity: 5 psu

Thermodynamics: Semtner (1976); dynamics: parameterization based on Bryan (1969), advection strictly with ocean currents; salinity: 6 psu 

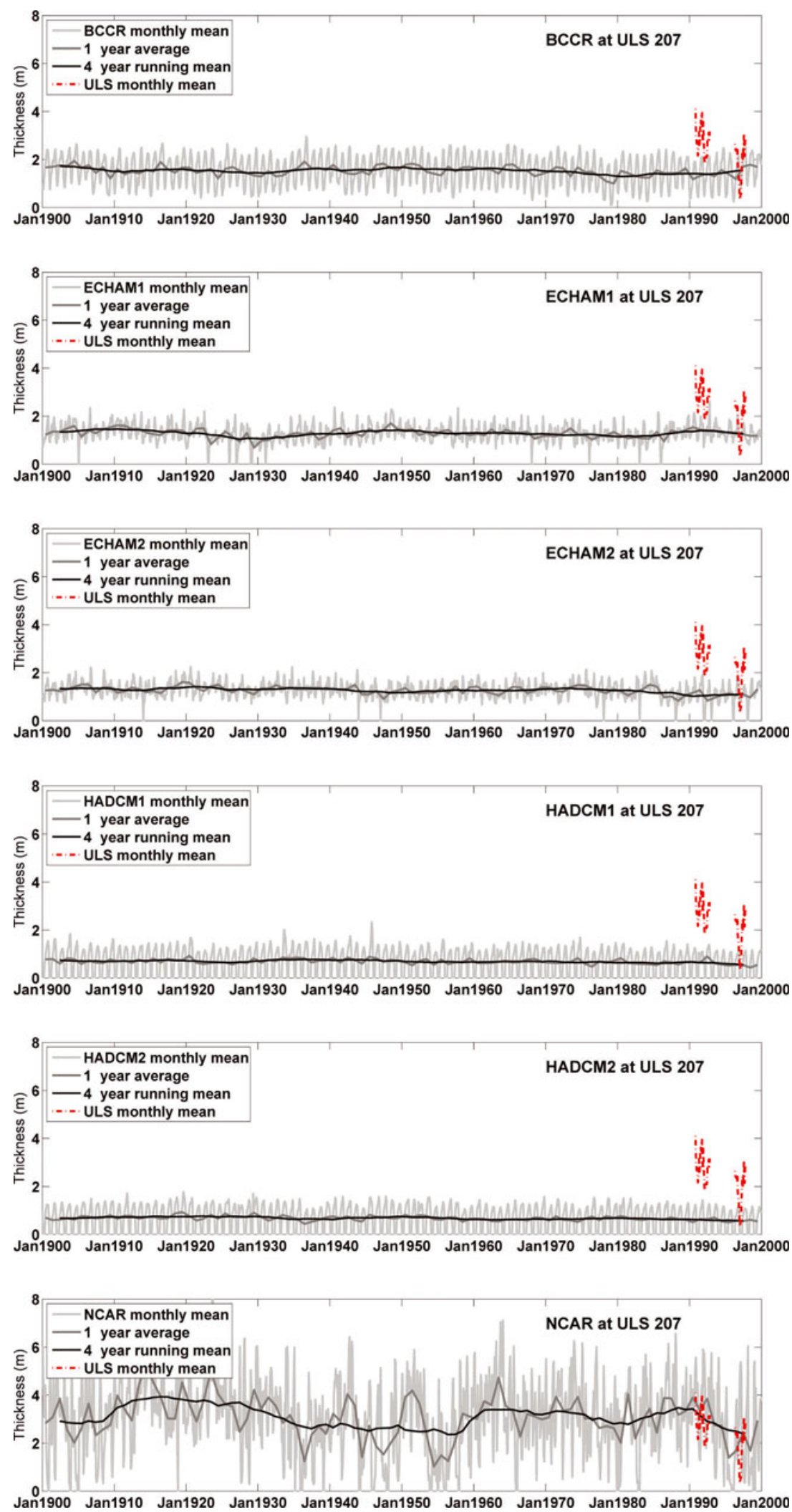

Fig. 2. Modeled sea-ice thickness at ULS 207; from top to bottom: BCCR, ECHAM1, ECHAM2, HADCM1, HADCM2 and NCAR. The lightgrey line shows the monthly mean thickness, the darker-grey line the annual averages, and the black line the 4 year running means of the annual averages. The red curve in each plot is the monthly mean ice thickness as observed by the ULS.

\section{DATA PROCESSING}

The ULS dataset contains a time series of ice drafts and flags to distinguish open water and sea ice. Neglecting drafts of $>20 \mathrm{~m}$ (assuming these are icebergs) and excluding data marked as open water, we calculated monthly averages.
Drafts $(d)$ were converted to thicknesses $(z)$ following Harms and others (2001):

$$
z=0.028+1.012 d
$$

Data from instruments deployed in different years at the 

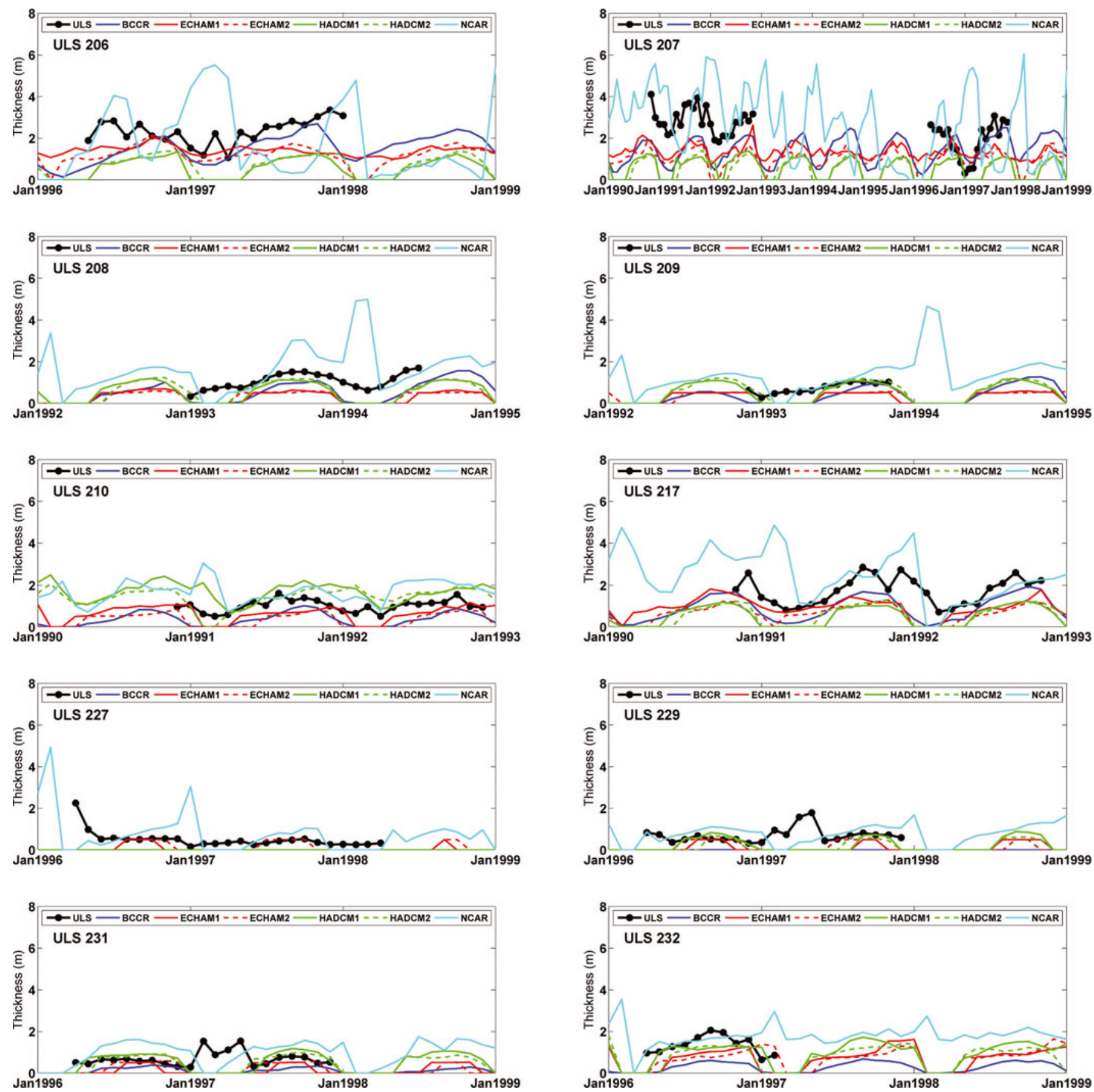

Fig. 3. Seasonal cycle of sea-ice thickness in the Weddell Sea at different ULS.

same location were combined by merging the records (ULS 207_2 and 207_4, ULS 227_3 and 227_4). ULS 212 and ULS 233 were excluded from the study, as they are positioned too close to the coast to expect reasonable model results. Consequently we have time series for ten different locations of 9-25 months length for comparison with model data.

Using the monthly averages, we also derived annual averages. Months with $<23$ days of obervations were not included; we assumed 23 days or more to be sufficient to represent the full month. Partial months at the beginning and the end of recordings were combined by calculating weighted averages.

To obtain comparable locations from the model data, we extracted for each ULS the ice-thickness and concentration data of the four gridboxes closest to the instrument position, and calculated their arithmetic mean. Except for BCCR, model ice thickness included open water $\left(z_{\text {in }}\right)$ and was converted to thicknesses excluding open water $\left(z_{\mathrm{ex}}\right)$ using a threshold ice concentration $(c)$ value:

$$
\begin{array}{ll}
z_{\mathrm{ex}}=\frac{z_{\mathrm{in}}}{c} & \text { for } c \geq 0.05 \\
z_{\mathrm{ex}}=0 & \text { for } c<0.05 .
\end{array}
$$

This threshold is introduced to prevent the generation of unnaturally high thicknesses when dividing by very low concentrations. Ice volume flux $\Phi_{\text {vol }}$ both for ULS and model data was derived by multiplying the ice thickness $z$ and concentration $c$ at each instrument location with the nearest 


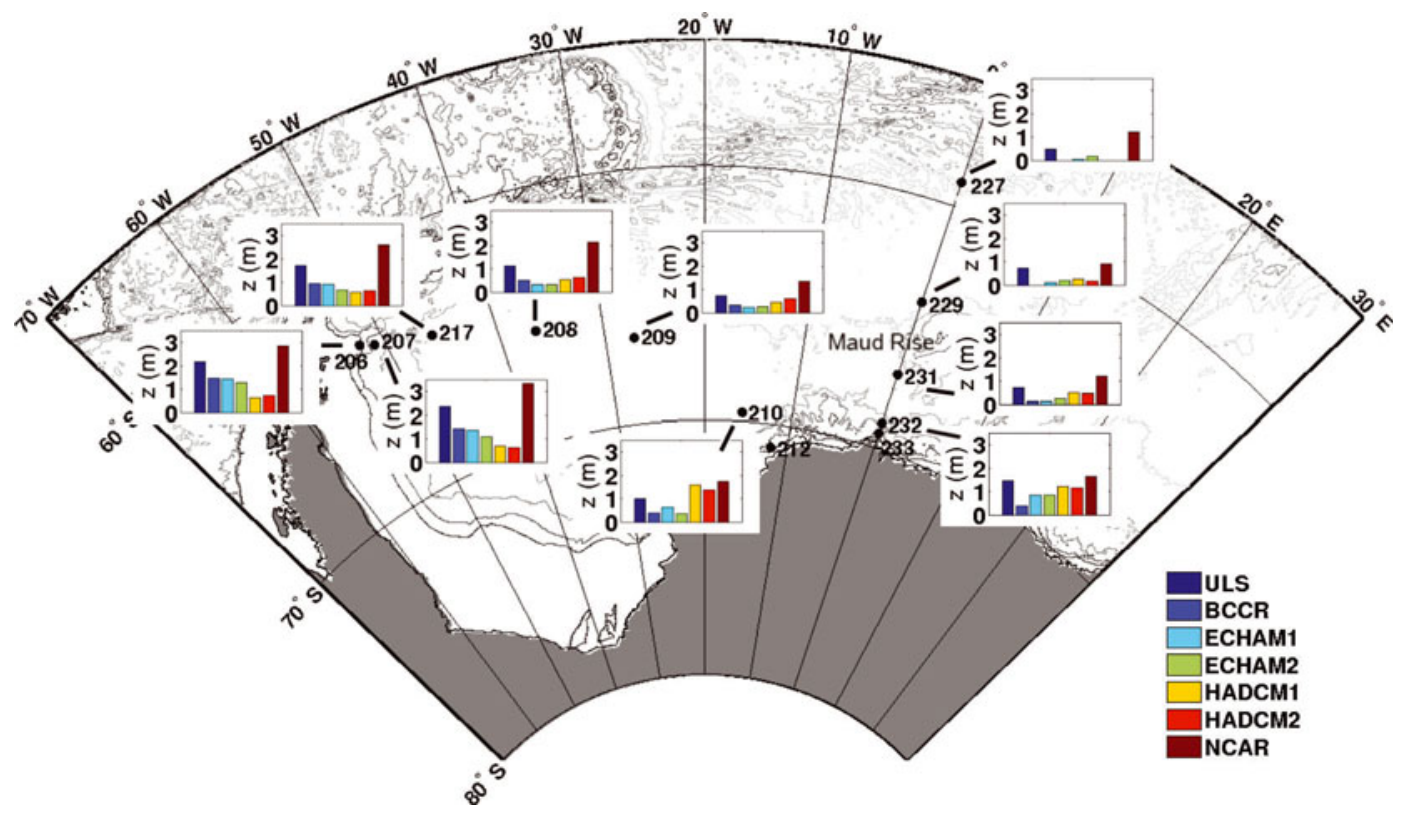

Fig. 4. Distribution of annual average ice thicknesses in the Weddell Sea.

ice velocity $v$ from the ice motion data:

$$
\Phi_{\mathrm{vol}}=z C V .
$$

To determine salt fluxes $\left(\Phi_{\text {sal }}\right)$, the following equation is used:

$$
\Phi_{\text {sal }}=\Phi_{\text {vol }} \rho_{\text {ice }} S_{\text {ice, }}
$$

where $\rho_{\text {ice }}$ is the density of sea ice, here assumed to be $910 \mathrm{~kg} \mathrm{~m}^{-3}$. The sea-ice salinity $S_{\text {ice }}$ varies (a) for the model data depending on the value used in each model (see Table 1) and (b) for the ULS data depending on the ice thickness. For the latter we follow Harms and others (2001) and use an empirical relationship:

$$
\begin{array}{ll}
S_{\text {ice }}=7.286-1.776 z & \text { for } z \leq 1.85 \mathrm{~m} \\
S_{\text {ice }}=4.0 & \text { for } z>1.85 \mathrm{~m} .
\end{array}
$$

Annual mean salt fluxes were derived in the same way as the annual averages of sea-ice thickness.

\section{ICE THICKNESS VARIABILITY}

In order to compare the model years of the $20 \mathrm{c} 3 \mathrm{~m}$ runs with observations collected over a limited time, we examined the simulated sea-ice thickness for the 100 model years which represent the 20th century. Figure 2 shows the time series for the location of ULS 207; the results discussed here are similar for the other locations and are not shown here. Generally, interannual variability is low, particularly as compared to the seasonal cycle. The models do not simulate any pronounced phases of several years of particularly thick or thin ice. The variability of the annual averages of 1900-99 is below $0.04 \mathrm{~m}$ for BCCR, ECHAM and HADCM. The only exception is NCAR, with a variability of $0.74 \mathrm{~m}$. Here, around 1920 and 1970 the ice is rather thick, while during the 1940s a phase of thin ice can be observed. NCAR also captures the higher/lower thickness in the early/late 1990s measured by ULS 207. Because of this relatively low interannual variability in the model data, we use data from the same time period as the ULS data for comparison.

\section{MODELED SEA-ICE THICKNESS AND CONCENTRATION IN COMPARISON TO ULS MEASUREMENTS}

As shown in Figures 3 and 4, the ULS observations show generally thicker ice in the inner Weddell Sea (transect 1) than along the prime meridian (transect 2). The thickest ice is observed over the continental slope near the tip of the Antarctic Peninsula at ULS 207 and at the eastern coast of the Weddell Sea at ULS 212 (not shown), with annual averages of 2.35 and $2.18 \mathrm{~m}$, respectively. In these regions, high ice-drift velocities, high ice concentrations and the proximity of the coast increase the formation of ridges, resulting in higher ice thicknesses. The ice is thinner along the northern part of the prime meridian (ULS 227, 229 and 231), where concentrations are lower, and at ULS 209, located in the central Weddell Sea, where, being in the centre of the Weddell Gyre, ice drift is slower. At most locations the seasonal cycle is clearly visible in the measurements: the ice is thicker in late austral winter, and thickness minima occur concurrently with concentration minima in austral summer (Figs 3 and 5). In the vicinity of Maud Rise (ULS 229 and 231), the thickest ice appears during summer, unlike the pattern recorded at the mooring. However, summer concentrations in this region are low (Fig. 5).

The sea-ice thickness and concentration from the different models are plotted in Figures 3 and 5, respectively. The models generally underestimate ice thickness (see Fig. 3; Table 2), particularly along the prime meridian. Also sea-ice concentrations are often too low (Fig. 5). At ULS 227, the northernmost mooring, BCCR and HADCM do not record any sea ice at all, placing the sea-ice edge further south. However, HADCM performs well in both runs in the eastern Weddell Sea (ULS 209 and 210) despite the low model resolution. Again, NCAR is different from the other models. While ice concentrations are in good agreement with observations, ice thickness is overestimated at all locations except for ULS 229. Along transect 1 the annual averages are up to $70 \%$ too high. 

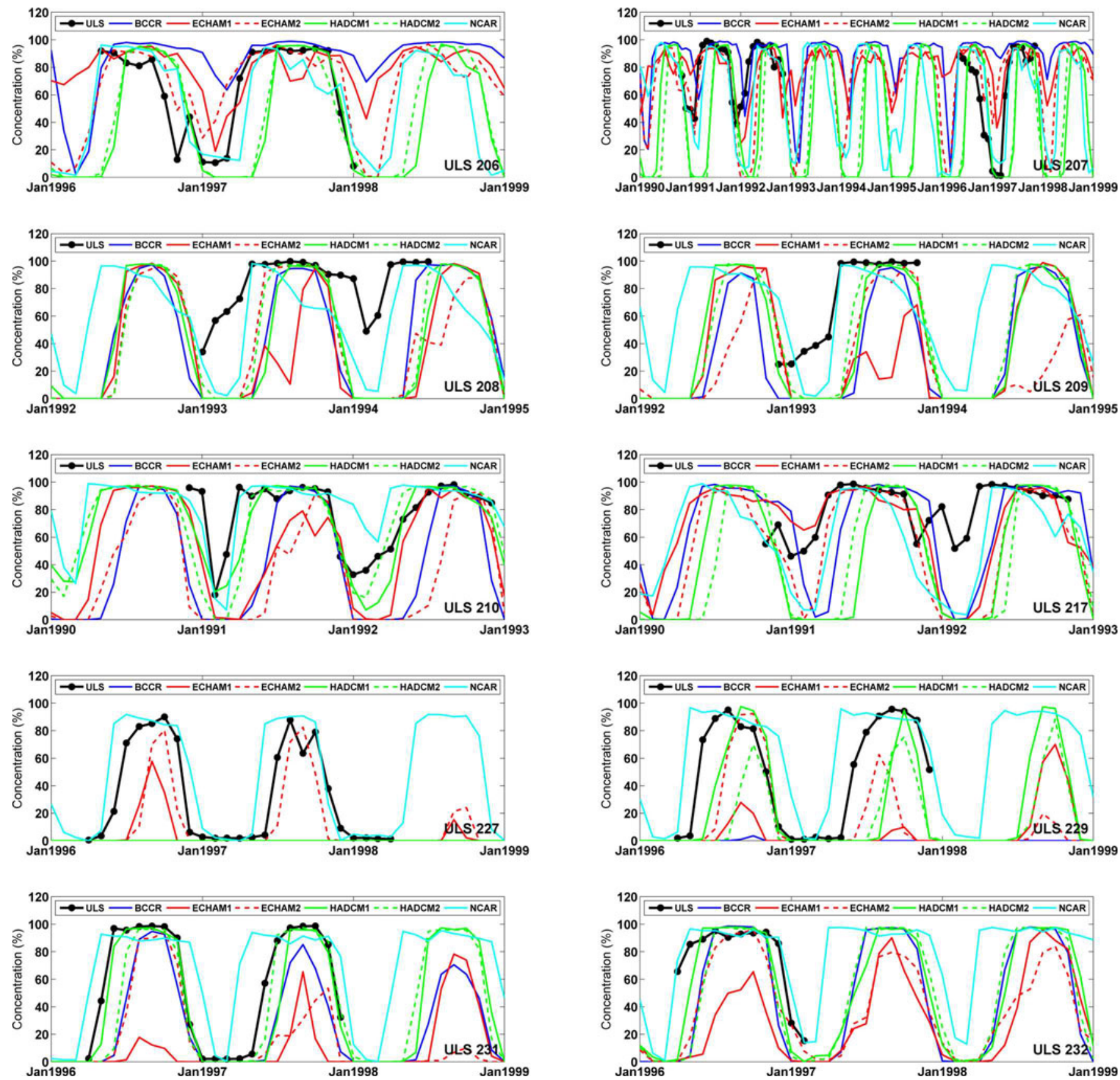

Fig. 5. Seasonal cycle of sea-ice concentration in the Weddell Sea at different ULS.

The seasonal cycle in sea-ice thickness is generally captured in the models (Figs 3 and 5). Only at moorings ULS 229 and 231, close to Maud Rise, does the high thickness at the end of summer not appear in the modeled cycles. While the timing of minima is good, the values are often underestimated for both ice thickness and concentration.

Summer thicknesses in NCAR are at times surprisingly high (e.g. February-March 1994; see Fig. 3). This is partly related to the conversion from $Z_{\text {in }}$ to $Z_{\text {ex }}$, but given the relatively high threshold value of $5 \%$ it is primarily a result of the model simulation.

As models are often validated against satellite observations of ice concentrations, we expect the models to be closer to observations. However, in the inner Weddell Sea, summer concentrations are mostly underestimated (see ULS 208, 210 and 217 in Fig. 5) while along the prime meridian winter concentrations are too low (Fig. 5; ULS 229 and 231).
In Figure 6 the annual averages reveal spatial differences in agreement: modeled concentrations fit the observations better in regions with high ice thickness and drift velocities (ULS 206, 207, 217, 210 and 232) than in the inner Weddell Sea and at the northern part of transect 2 (ULS 208, 209, $227,229)$.

\section{ICE TRANSPORT AND SALT FLUXES}

In Figure 7, ice volume transport time series for three locations on transect 1 are shown. The gaps in the time series are due to missing or low-quality satellite data (see http://imkhp7.physik.uni-karlsruhe.de/ eisatlas). At ULS 207, which is near the tip of the Antarctic Peninsula, transports are highest. At ULS 208 and 210 in the centre and near the eastern boundary of the Weddell Sea, transports are lower, which corresponds to the general structure and 


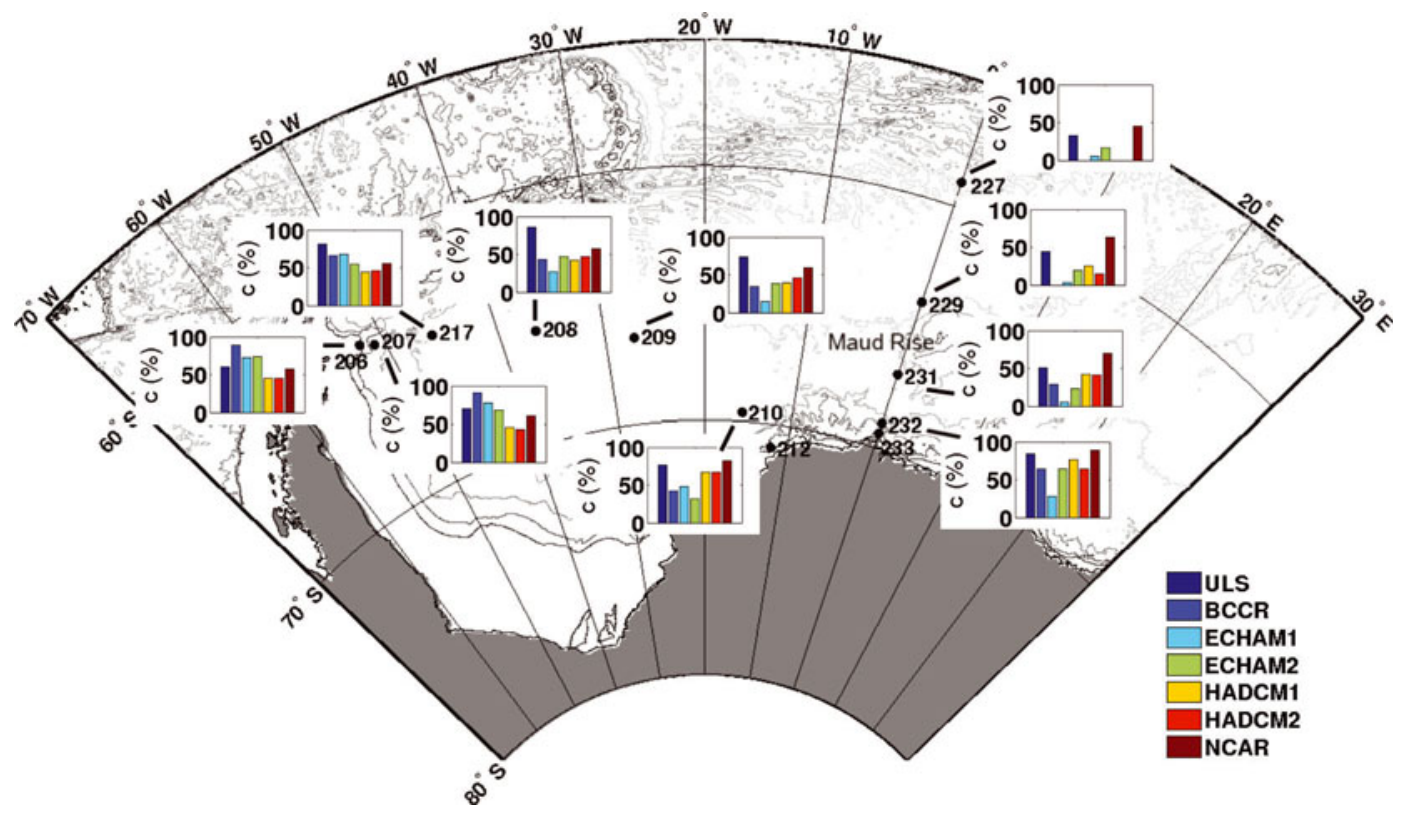

Fig. 6. Distribution of annual average ice concentration in the Weddell Sea.

velocities in the Weddell Gyre (Fahrbach and others, 1994; Muench and Gordon, 1995). The pattern of underestimation in ice thickness is carried forward but slightly modified as ice concentrations are included in the calculations (see Equation (3)). Thus the ice volume transport at ULS 207 is too low, but transports in the inner and eastern Weddell Sea are closer to observations or slightly too high.

Figure 8 shows the direction of the ice volume transports and the magnitude of the associated salt transports along transect 1 (Table 3). For calculations of salt fluxes, the seaice salinities in the models (see Table 1) need to be considered. For thin ice less than $1 \mathrm{~m}$ thick (typically new or first-year ice), observed salinities are high with values of up to 7 . On average, however, salinities range between 4 and 6 . The models are within this range, with fixed salinities of 4 (BCCR, NCAR), 5 (ECHAM) and 6 (HADCM). However, they cannot distinguish between higher salt transports due to drift of new and therefore thin ice and lower transports by thick multi-year ice. This may explain the notable differences in agreement between the different locations and models: in the central and eastern Weddell Sea, the underestimation of thicknesses and concentrations by BCCR and ECHAM and the low salinities enhance the underestimation of salt transports, while near the Antarctic Peninsula high thicknesses and concentrations and for ECHAM higher than observed salinities result in overestimation.

\section{SUMMARY AND CONCLUSIONS}

In this study, we compared observational sea-ice thickness data from ULS instruments in the Weddell Sea to modeled thicknesses and calculated ice volume and salt transports. We found that most of the models underestimate ice thickness, the exception being the NCAR CCSM3 model. This is valid both for the variability over the 100 years representing the 20th century in the $20 \mathrm{c} 3 \mathrm{~m}$ run and for the annual average thicknesses for the periods where ULS measurements are available. When looking at volume and salt transports, simulated ice concentrations and fixed values for sea-ice salinity modify the distribution, and both overand underestimation occurs.

As mentioned earlier, this study is limited to comparing only a few model gridcells with ULS data and for only a few models, and results may not be applicable to the rest of the sea-ice region or other models. However, the Weddell Sea is the largest source of Antarctic Bottom Water (Rintoul, 1998), so it is important to evaluate how well the salt fluxes from sea-ice processes are represented in global models. The salt fluxes which help drive the ocean models are directly

Table 2. Annual average ice thickness (m)

\begin{tabular}{|c|c|c|c|c|c|c|c|c|c|c|}
\hline \multirow[b]{2}{*}{ Model } & \multicolumn{10}{|c|}{ Instrument No. } \\
\hline & 206 & 207 & 208 & 209 & 210 & 217 & 227 & 229 & 231 & 232 \\
\hline ULS & 2.16 & 2.35 & 1.13 & 0.72 & 1.02 & 1.72 & 0.48 & 0.74 & 0.74 & 1.45 \\
\hline BCCR & 1.45 & 1.42 & 0.52 & 0.32 & 0.38 & 0.93 & 0 & 0.00 & 0.15 & 0.38 \\
\hline ECHAM 1 & 1.44 & 1.37 & 0.29 & 0.25 & 0.58 & 0.90 & 0.06 & 0.10 & 0.13 & 0.79 \\
\hline ECHAM 2 & 1.29 & 1.09 & 0.33 & 0.25 & 0.33 & 0.66 & 0.17 & 0.19 & 0.26 & 0.85 \\
\hline HADCM 1 & 0.59 & 0.67 & 0.53 & 0.46 & 1.60 & 0.52 & 0 & 0.23 & 0.52 & 1.22 \\
\hline HADCM 2 & 0.69 & 0.62 & 0.63 & 0.56 & 1.37 & 0.61 & 0 & 0.17 & 0.48 & 0.93 \\
\hline NCAR & 2.83 & 3.35 & 1.88 & 0.87 & 1.74 & 2.25 & 0.57 & 0.69 & 0.99 & 1.64 \\
\hline
\end{tabular}



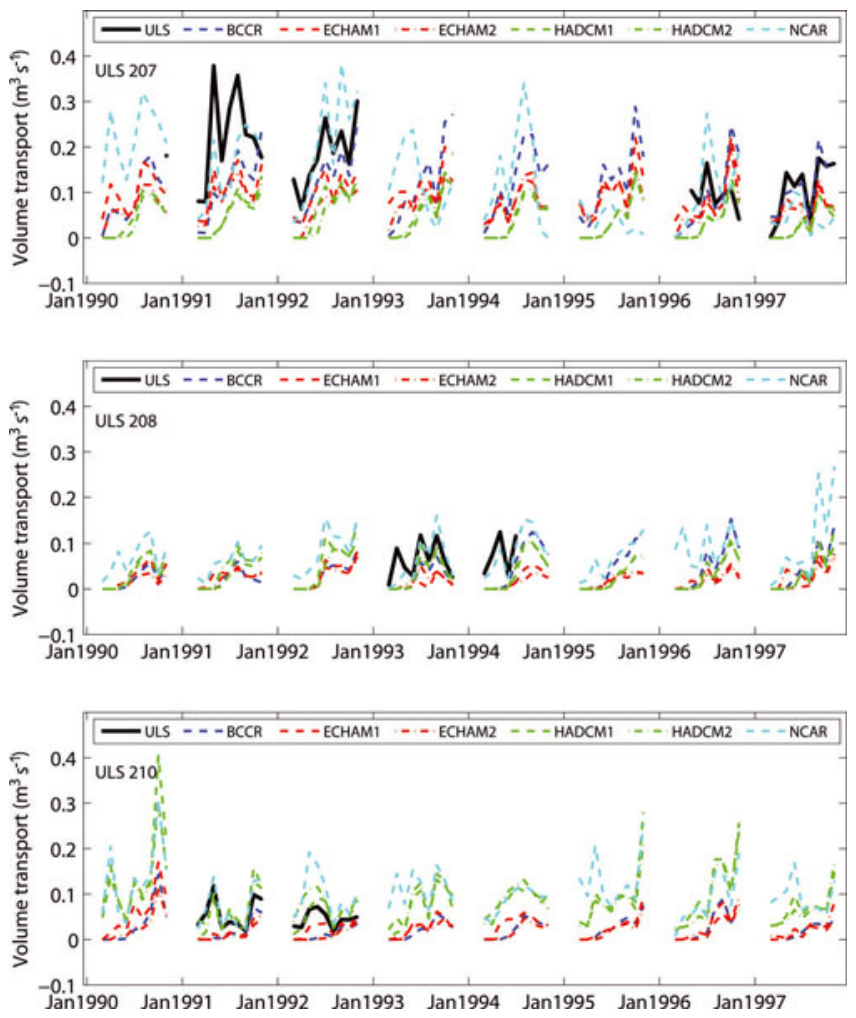

Fig. 7. Sea-ice volume transport in the Weddell Sea at different ULS.

related to both the sea-ice thickness and the ice salinities. Initiatives are underway to improve observational datasets which are available for comparison with models, but because of the large variation in time and spatial scales direct comparisons are inevitably difficult.
Table 3. Annual averages of salt mass transport $\left(\mathrm{kg} \mathrm{s}^{-1}\right)$

\begin{tabular}{lccclll}
\hline \multicolumn{7}{c}{ Instrument No. } \\
Dataset & 206 & 207 & 208 & 209 & 210 & 217 \\
\hline ULS & 358.2 & 545.6 & 305.7 & 233.4 & 249.2 & 538.5 \\
BCCR & 491.3 & 600.5 & 139.7 & 88.8 & 86.6 & 497.9 \\
ECHAM 1 & 332.4 & 405.6 & 46.6 & 22.2 & 90.5 & 336.3 \\
ECHAM 2 & 314.7 & 324.1 & 71.8 & 64.1 & 55.3 & 251.7 \\
HADCM 1 & 192.5 & 250.3 & 149.9 & 148.7 & 336.1 & 294.2 \\
HADCM 2 & 209.5 & 248.0 & 179.1 & 197.0 & 355.9 & 319.6 \\
NCAR & 264.4 & 487.9 & 230.0 & 161.8 & 304.8 & 427.9 \\
& & & & & & \\
\hline
\end{tabular}

To validate the sea ice in global models, sea-ice extent and concentration are often used because there are global datasets available spanning several decades. However, this is not a good indicator to evaluate ocean salt fluxes due to seaice formation and melt. While the development of ice thickness due to ridging and rafting is still difficult to simulate by sea-ice models, with only a few exceptions the ULSderived ice thickness was much larger than the model data in the locations presented here. In several cases, the salt mass flux from the model was closer to the observational estimate than the sea-ice thickness. This result indicates the importance of looking at other model parameters in addition to ice thickness when evaluating the model data. As the quantity and quality of data on sea-ice thickness improve, it will be important to evaluate the ability of sea-ice models to represent not only the sea-ice thickness, but the associated salinity of the sea ice. With more data of ice drift becoming available (e.g. from buoys, drift stations and satellite measurements), validation and improvement of ice dynamics

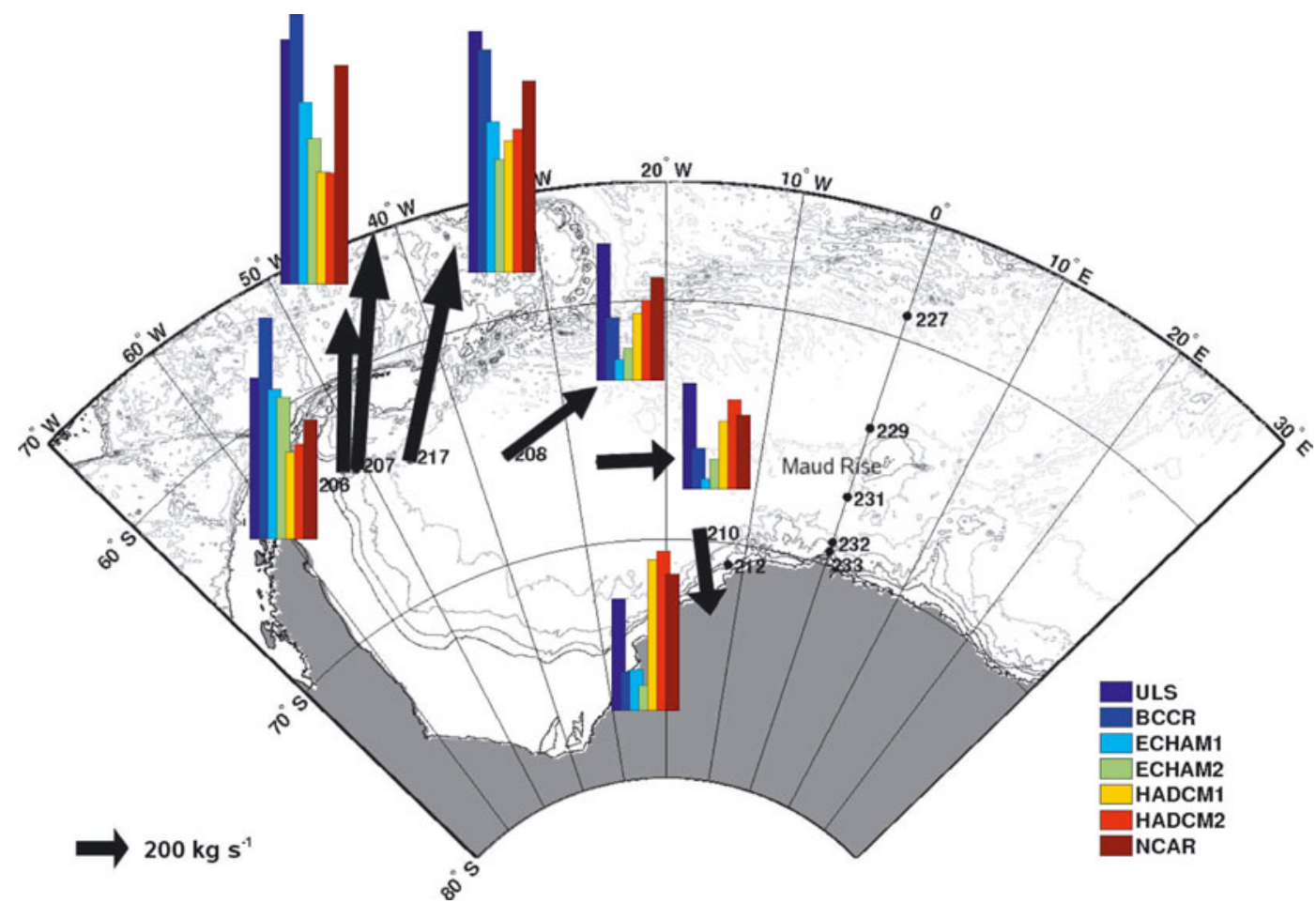

Fig. 8. Annual average salt transports along the transect across the Weddell Sea. The black arrows show magnitude and direction of ULS measured transports; the histograms then give the magnitude of the modeled transports as well. The dark-blue bars correspond in length to the arrows. 
and drift in models is also of importance to correct ice thickness and salt fluxes.

\section{ACKNOWLEDGEMENTS}

The model data were supplied by the Program for Climate Model Diagnosis and Intercomparison (PCMDI). We thank the various modeling groups for making their simulations available for analysis. The ULS data were archived at NSIDC by the AWI. Sea-ice motion data were obtained from the Atlas of Antarctic Sea Ice Drift. Comments by S. Laxon and two anonymous reviewers are gratefully acknowledged. This study was funded in part by the World Climate Research Program (WCRP) Climate and Cryosphere Project (CLiC) Office.

\section{REFERENCES}

Arzel, O., T. Fichefet and H. Goosse. 2005. Sea ice evolution over the 20th and 21st centuries as simulated by current AOGCMs. Ocean Model., 12(3-4), 401-415.

Bitz, C.M. and W.H. Lipscomb. 1999. An energy-conserving thermodynamic model of sea ice. J. Geophys. Res., 104(C7), $15,669-15,677$.

Bryan, K. 1969. Climate and the ocean circulation. III. The ocean model. Mon. Weather Rev., 97(11), 806-827.

Connolley, W.M. 2005. Sea ice concentrations in the Weddell Sea: a comparison of SSM/I, ULS and GCM data. Geophys. Res. Lett., 32(7), L07501. (10.1029/2004GL021898.)

Drange, $\mathrm{H}$ and Simonsen, K. 1996. Formulation of air-sea fluxes in ESOP2 version of MICOM. Bergen, Nansen Environmental and Remote Sensing Center. (Technical Report 25.)

Drinkwater, M.R., X. Liu and S. Harms. 2001. Combined satelliteand ULS-derived sea-ice flux in the Weddell Sea, Antarctica. Ann. Glaciol., 33, 125-132.

Fahrbach, E., G. Rohardt, M. Schröder and V. Strass. 1994. Transport and structure of the Weddell Gyre. Ann. Geophys., 12(9), 840-855.

Gordon, A.L. and V.V. Lukin. 1992. Ice Station Weddell \#1. Antarct. J. US, 27(5), 97-99.

Haas, C., S. Gerland, H. Eicken and H. Miller. 1997. Comparison of sea-ice thickness measurements under summer and winter conditions in the Arctic using a small electromagnetic induction device. Geophysics, 62(3), 749-757.

Harder, M. 1996. Dynamik, Rauhigkeit und Alter des Meeeises in der Arktis. (PhD thesis, Alfred-Wegener-Institut für Polar- und Meeresforschung.)

Harms, S., E. Fahrbach and V.H. Strass. 2001. Sea ice transports in the Weddell Sea. J. Geophys. Res., 106(C5), 9057-9073.

Hibler, W.D., III. 1979. A dynamic thermodynamic sea ice model. J. Phys. Oceanogr., 9(7), 815-846.

Holland, M.M. and M.N. Raphael. 2005. Twentieth century simulation of the southern hemisphere climate in coupled models. Part II: sea ice conditions and variability. Climate Dyn., 26(2-3), 229-245.

Hunke, E.C. and J.K. Dukowicz. 1997. An elastic-viscous-plastic model for sea ice dynamics. J. Phys. Oceanogr., 27(9), 1849-1867.
Jeffries, M.O. and U. Adolphs. 1997. Early winter snow and ice thickness distribution, ice structure and development of the western Ross Sea pack ice between the ice edge and the Ross Ice Shelf. Antarct. Sci., 9(2), 188-200.

Kwok, R., G.F. Cunningham, H.J. Zwally and D. Yi. 2006. ICESat over Arctic sea ice: interpretation of altimetric and reflectivity profiles. J. Geophys. Res., 111(C6), C06006. (10.1029/ 2005JC003175.)

Lange, M.A. and H. Eicken. 1991. The sea ice thickness distribution in the northwestern Weddell Sea. J. Geophys. Res., 96(C3), 4821-4837.

Laxon, S., N. Peacock and D. Smith. 2003. High interannual variability in sea ice thickness in the Arctic region. Nature, 425(6961), 947-950.

Lemke, P., W.D. Hibler, G. Flato, M. Harder and M. Kreyscher. 1997. On the improvement of sea-ice models for climate simulations: the Sea Ice Model Intercomparison Project. Ann. Glaciol., 25, 183-187.

Melling, H., P.H. Johnston and D.A. Riedel. 1995. Measurements of the underside topography of sea ice by moored subsea sonar. J. Atmos. Oceanic Technol., 12(3), 589-602.

Muench, R.D. and A.L. Gordon. 1995. Circulation and transport of water along the western Weddell Sea margin. J. Geophys. Res., 100(C9), 18,503-18,515.

Parkinson, C.L., K.Y. Vinnikov and D.J. Cavalieri. 2006. Evaluation of the simulation of the annual cycle of Arctic and Antarctic sea ice coverages by 11 major global climate models. J. Geophys. Res., 111(C7), C07012. (10.1029/2005JC003408.)

Perovich, D.K., T.C. Grenfell, J.A. Richter-Menge, B. Light, W.B. Tucker, III and H. Eicken. 2003. Thin and thinner: ice mass balance measurements during SHEBA. J. Geophys. Res., 108(C3), 8050. (10.1029/2001JC001079.)

Rintoul, S.R. 1998. On the origin and influence of Adélie Land bottom water. In Jacobs, S.S. and R.F. Weiss, eds. Ocean, ice and atmosphere: interactions at the Antarctic continental margin. Washington, DC, American Geophysical Union, 151-172. (Antarctic Research Series 75.)

Rothrock, D.A., Y. Yu and G.A. Maykut. 1999. Thinning of the Arctic sea-ice cover. Geophys. Res. Lett., 26(23), 3469-3472.

Semtner, A.J., Jr. 1976. A model for the thermodynamic growth of sea ice in numerical investigations of climate. J. Phys. Oceanogr., 6(5), 379-389.

Strass, V.H. and E. Fahrbach. 1998. Temporal and regional variation of sea ice draft and coverage in the Weddell Sea obtained from upward looking sonars. In Jeffries, M.O., ed. Antarctic sea ice: physical processes, interactions and variability. Washington, DC, American Geophysical Union, 123-139. (Antarctic Research Series 74.)

Strass, V.H., W.H. Tian and M. Nemoto. 1998. Measuring sea ice draft and coverage with moored upward looking sonars. DeepSea Res. I, 45(4), 795-818.

Timmermann, R., A. Worby, H. Goosse and T. Fichefet. 2004. Utilizing the ASPeCt sea ice thickness data set to evaluate a global coupled sea ice-ocean model. J. Geophys. Res., 109(C7), C07017. (10.1029/2003JC002242.)

Vinje, T., N. Nordlund and Å.S. Kvambekk. 1998. Monitoring ice thickness in Fram Strait. J. Geophys. Res., 103(C5), 10,437-10,450.

Wadhams, P. and R.J. Horne. 1980. An analysis of ice profiles obtained by submarine sonar in the Beaufort Sea. J. Glaciol., 25(93), 401-424. Erratum: 27(96), 1981, 367. 